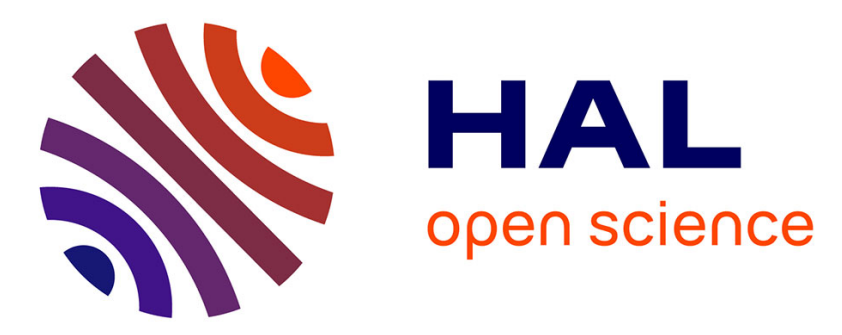

\title{
Hydrogen/Deuterium Exchange Mass Spectrometry Reveals Mechanistic Details of Activation of Nucleoside Diphosphate Kinases by Oligomerization
}

Alain Dautant, Philippe Meyer, Florian Georgescauld

\section{- To cite this version:}

Alain Dautant, Philippe Meyer, Florian Georgescauld. Hydrogen/Deuterium Exchange Mass Spectrometry Reveals Mechanistic Details of Activation of Nucleoside Diphosphate Kinases by Oligomerization. Biochemistry, 2017, 10.1021/acs.biochem.7b00282 . hal-01527330

\section{HAL Id: hal-01527330 \\ https: / hal.sorbonne-universite.fr/hal-01527330}

Submitted on 24 May 2017

HAL is a multi-disciplinary open access archive for the deposit and dissemination of scientific research documents, whether they are published or not. The documents may come from teaching and research institutions in France or abroad, or from public or private research centers.
L'archive ouverte pluridisciplinaire HAL, est destinée au dépôt et à la diffusion de documents scientifiques de niveau recherche, publiés ou non, émanant des établissements d'enseignement et de recherche français ou étrangers, des laboratoires publics ou privés. 


\title{
Hydrogen/Deuterium Exchange Mass Spectrometry reveals Mechanistic Details of Nucleoside Diphosphate Kinases Activation by Oligomerization
}

\author{
Alain Dautant ${ }^{*}, \dagger$ Philippe Meyer, ${ }^{\ddagger}$ and Florian Georgescauld ${ }^{\star, \ddagger}$ \\ Université de Bordeaux, CNRS, Institut de Biochimie et Génétique Cellulaires, UMR5095, \\ Bordeaux, France and Sorbonne Universités, UPMC Univ. Paris 06, CNRS, Laboratoire de \\ Biologie Moléculaire et Cellulaire des Eucaryotes, UMR8226, Institut de Biologie Physico- \\ Chimique, 13 rue Pierre et Marie Curie, 75005 Paris, France
}

\begin{abstract}
Most oligomeric proteins become active only after assembly, but why oligomerization is required to support function is not well understood. Here, we address this question using the WT and a destabilized mutant (D93N) of the hexameric nucleoside diphosphate kinase from the pathogen Mycobacterium tuberculosis (Mt-NDPK). The conformational dynamics and oligomeric states of each were analyzed during unfolding/folding by Hydrogen/Deuterium exchange mass spectrometry (HDX-MS) at peptide resolution and by additional biochemical techniques. We found that WT and D93N native hexamers present a stable core and a flexible periphery, the latter being more flexible for the destabilized mutant. Stable but inactive species formed during unfolding of D93N and folding of WT were characterized. For the first time, we show that both of these species are native-like dimers, each of its monomers having a major subdomain folded, while a minor subdomain $\left(K p n / \alpha_{0}\right)$ remains unfolded. The $K p n / \alpha_{0}$ subdomain, which belongs to the catalytic site, becomes structured only upon hexamerization, explaining why oligomerization is required for NDPK activity. Further HDX-MS studies are necessary to establish the general activation mechanism for other homo-oligomers.
\end{abstract}

\footnotetext{
* To whom correspondence should be addressed. Alain Dautant, Université de Bordeaux, CNRS, Institut de Biochimie et Génétique Cellulaires, UMR 5095, 146 rue Léo Saignat, 33077 Bordeaux, France. E-mail: a.dautant@ibgc.cnrs.fr. Florian Georgescauld, Sorbonne Universités, UPMC Univ. Paris 06, CNRS, Laboratoire de Biologie Moléculaire et Cellulaire des Eucaryotes, UMR8226, Institut de Biologie Physico-Chimique, 13 rue Pierre et Marie Curie, 75005 Paris, France. E-mail: georgescauld@ibpc.fr

${ }^{\dagger}$ IBGC, UMR 5095 CNRS Université de Bordeaux, Bordeaux, France

^IBPC, UMR 8226 CNRS Université Pierre et Marie Curie, Paris, France
} 


\section{INTRODUCTION}

Depending on the organism, 40 to $60 \%$ of proteins assemble and become functional after forming oligomeric complexes. ${ }^{(1,2)}$ These proteins must, within a well determined tridimensional complex structure, subtly balance thermodynamic stability with conformational flexibility. ${ }^{(3,4)}$ Thermodynamic stability is required to maintain a protein's activity throughout its lifetime while preventing proteolysis or aggregation. In parallel, flexibility is necessary for newly synthesized chains to acquire the native conformation, to assemble and afterwards for the protein to perform its function. How oligomerization induces a protein's “functionality" and how a protein's function, thermodynamic stability and conformational flexibility relate to each other are poorly understood, essentially due to lack of experimental information on the dynamic aspects. Since a single analytical method cannot provide information on a large panel of the physico-chemical properties of proteins, multi-technique approaches and development of new time and space resolved techniques appear essential in this understanding. ${ }^{(5-8)}$

Hydrogen/Deuterium exchange detected by mass spectrometry (HDX-MS) is a methodology applied to proteins in recent years for investigating their properties, at peptide resolution, such as dynamics, conformational changes, post-translational modifications, viral capsid assembly, spontaneous and assisted folding, and interactions with partners or ligands. ${ }^{(9-13)}$ The method is applied to proteins in solutions mimicking their physiological environment and relies on the natural property that proteins rapidly exchange their solvent accessible backbone amide hydrogens that are not involved in stable $\mathrm{H}$-bonds. Exposure of the protein of interest into a $\mathrm{D}_{2} \mathrm{O}$-containing solvent environment induces the replacement of labile accessible backbone hydrogen $\left({ }^{1} \mathrm{H}, \mathrm{H}\right)$ atoms with deuterium $\left({ }^{2} \mathrm{H}, \mathrm{D}\right)$. The exchange is measured by MS after protein digestion and interpreted in the view of the structure. The advantages of HDX-MS are that it requires only a small amount of material (in the pmol range), that it has great resolution and sensitivity, that it allows for an accessible mass range of up to $10^{6} \mathrm{Da}$, that it allows high speed analysis and that it is a nonensemble technique; each single spectrum contains extractible information about all discrete coexisting states of the protein of interest. By massively increasing its interest in protein therapeutics within these last years, the biopharmaceutical industry became particularly interested in improving and developing spatially resolved analytical techniques like HDX-MS for its needs in both research and quality control. ${ }^{(14,15)}$ Since so far HDX-MS was mostly implemented on monomeric proteins ${ }^{(16-}$ 
22) and only a few studies have been conducted on homo-oligomeric proteins ${ }^{(23-27)}$ or protein complexes, ${ }^{(28-31)}$ efforts have to be continued for extracting the dynamic determinants of complexes.

Nucleoside diphosphate kinase (NDPK) is a multifunctional protein which catalyzes the gammaphosphate transfer from nucleoside triphosphate to nucleoside diphosphate ${ }^{(32)}$ in order to maintain equilibrium between the pools of nucleoside triphosphates (NDP/NTP). Several isoforms are found in eukaryotes, ${ }^{(33)}$ isoform 1 (called $\mathrm{nm} 23 \mathrm{~A}$ ) being the first metastasis suppressor described in humans. $^{(34-36)}$ Additionally, NDPK also acts as a protein histidine kinase, ${ }^{(37-39)}$ and recent studies have shown that by interacting with and providing GTP to dynamins, NDPK is involved in membrane-remodeling events. ${ }^{(40,41)}$ Like many enzymes, NDPKs are non-allosteric oligomers, but in vitro and in vivo studies suggest that their assembly is required for kinase activity or metastasis suppression function. ${ }^{(42-44)}$ Many aspects of the kinase activity mechanism are now understood from a structural point of view, ${ }^{(32)}$ namely, the role of amino acids involved in the catalysis, but the requirement for assembly to become functional is still unclear and remains to be elucidated. ${ }^{(42,43)}$

NDPKs contain ferredoxin-like folds ${ }^{(45)}$ which assemble first as dimers and then as tetramers or hexamers. ${ }^{(46-48)}$ Tetramers are present in gram-negative bacteria and archaea, while hexamers are present in gram-positive bacteria and eukaryotes. Hexamers represent the most abundant type of oligomerization, which specifically relies on the well conserved surface loop that carries the site of the natural "Killer of prune" mutation (Kpn-loop) (Figures 1, S1). In addition, the stabilization of hexamers by subunit interactions has been studied. ${ }^{(49-53)}$ Crystallographic structures of severalNDPK mutants provide detailed understanding of the WT stabilization mechanism, ${ }^{(53,54)}$ but provide little understanding as to why oligomerization is necessary for function. So, we realized that by combining stability aspects with the study of their dynamic properties, we would improve this understanding. 

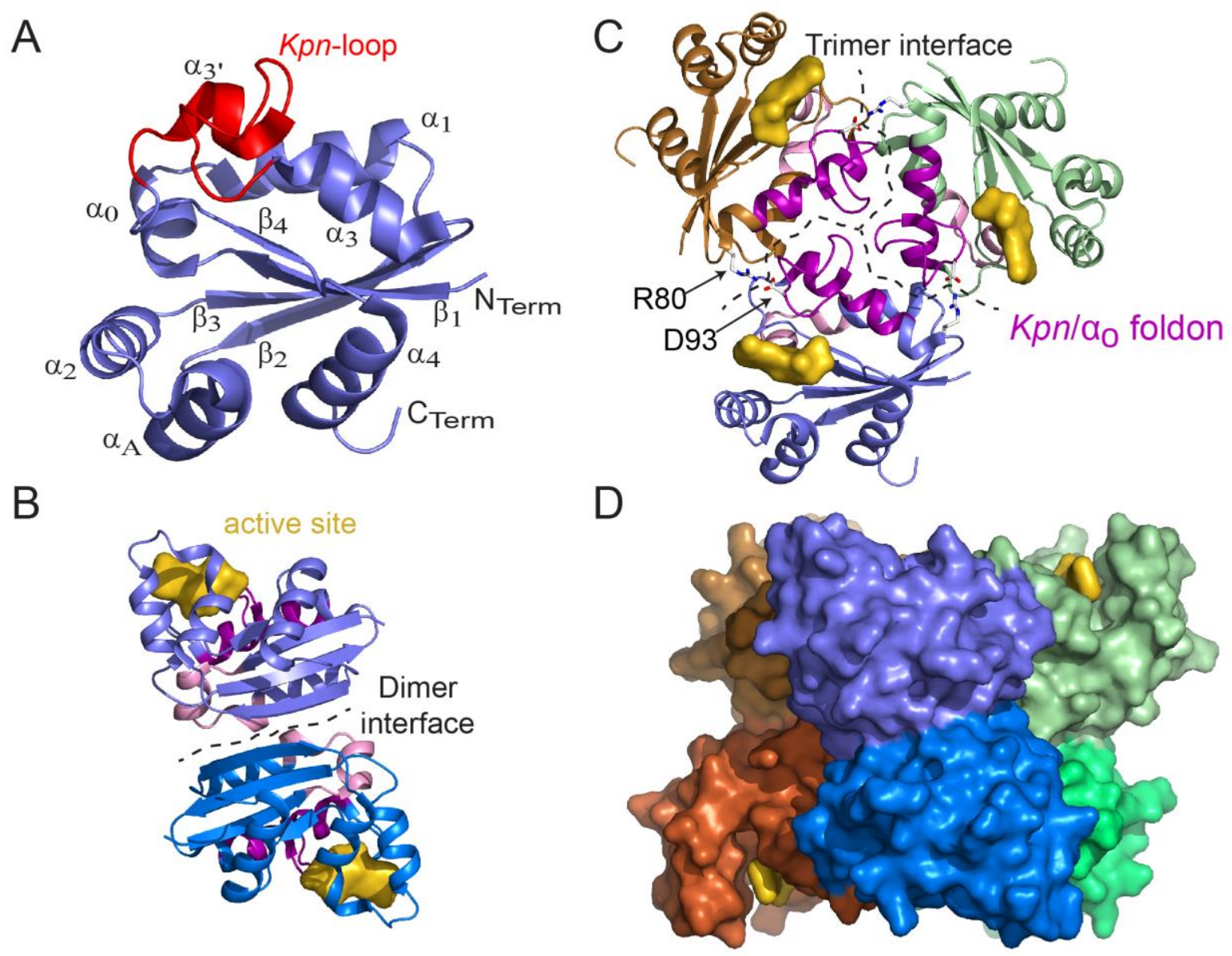

\section{FIGURE 1}

Mycobacterium tuberculosis (Mt), the pathogenic bacteria responsible of tuberculosis, possesses only one NDPK isoform (Mt-NDPK), which is hexameric (Figures $1, \mathrm{~S} 1) .{ }^{(49)}$ In addition to its kinase function, $M t$-NDPK binds $\mathrm{DNA}^{(55)}$ and also blocks phagosome maturation in murine macrophages leading to evasion of innate immunity. ${ }^{(56)}$ The escape mechanism is unknown, but efficient intracellular survival of $M t$ requires a strong thermodynamic stability of proteins. ${ }^{(57)}$ We recently showed in vitro that isolated sub-hexameric assemblies of $M t$-NDPK are inactive, complete assembly being essential for function. ${ }^{(53)}$ By combining crystallography and biochemistry, we also demonstrated that hexamer's high thermostability $\left(76^{\circ} \mathrm{C}\right)$ is dependent on six inter-subunit R80-D93 salt bridges. ${ }^{(54)}$ The point mutation $\mathrm{D} 93 \mathrm{~N}$ reduces the melting point by $28^{\circ} \mathrm{C}$, without significant alteration of the hexameric 3D structure or enzymatic properties. ${ }^{(53)}$ The link between the protein's function, stability and oligomerization is still an open question. 
Here, we show why the full oligomeric state is required for and affects protein function, as demonstrated by the study of WT and D93N $M t$-NDPK. In addition to the classical biochemistry methods (fluorescence, enzymology, size exclusion chromatography), we use the HDX-MS technique to reveal the overall and local structure and dynamics of NDPK by monitoring amide hydrogen atoms in polypeptides. We show that both native hexamers are stable, without in/out subunit exchange, but that the D93N destabilizing mutation increases the flexibility at the hexamer surface. Inactive dimers which accumulate during folding of WT and D93N, as well as during D93N unfolding were analyzed. Strikingly, differences in conformational flexibility between hexamers and dimers explain why hexamerization is required for kinase activity.

\section{MATERIALS AND METHODS}

Reagents. Chemicals were of the highest purity grade from Sigma. Solutions of urea were freshly prepared for each experiment.

Proteins and enzymatic assays. WT and D93N $M t$-NDPK were expressed without tag, using a pET24 vector (Novagen) in BL21-CodonPlus ${ }^{\circledR}$ (DE3)-RIL (Stratagene) strain. Transformed cells were induced at $37^{\circ} \mathrm{C}$ with $1 \mathrm{mM}$ IPTG for $6 \mathrm{~h}$ in the presence of $80 \mu \mathrm{g} / \mathrm{mL}$ kanamycin and the purification steps were carried out at $4^{\circ} \mathrm{C}$ as previously described. ${ }^{(53)}$ After sonication and centrifugation, the soluble fraction containing $M t$-NDPK was DNase-treated, and the extract was applied to a Q-Sepharose column equilibrated with $100 \mathrm{mM}$ Tris-HCl, pH 7.4. The enzyme was eluted with a linear gradient of 0 to $0.8 \mathrm{M} \mathrm{NaCl}$ in the same buffer. Active fractions were precipitated into $80 \%$ saturated ammonium sulfate (AS) and further purified by salting-out chromatography on a Sepharose 6B column equilibrated with $80 \%$ AS, 100 mM Tris- $\mathrm{HCl}, \mathrm{pH}$ 7.4. The protein was eluted by decreasing AS concentration from $80 \%$ to $20 \%$ in the same buffer. The active fractions were dialyzed against $100 \mathrm{mM}$ Tris-HCl, $\mathrm{pH} 7.4$, and further purified on a Source 15Q column, under the conditions described for the Q-Sepharose chromatography. The enzymes were precipitated by dialysis against a saturated solution of AS, recovered by centrifugation and further purified by size-exclusion chromatography on a Sephacryl S-200 column equilibrated with $0.2 \mathrm{M}$ sodium phosphate buffer, $\mathrm{pH}$ 7.0. The final hexameric preparations were kept frozen in 50 $\mathrm{mM}$ Tris- $\mathrm{HCl}, \mathrm{pH} 7.4$ at $-80^{\circ} \mathrm{C}$.

The size-exclusion chromatography (SEC) was performed in $20 \mathrm{mM}$ phosphate buffer, 150 $\mathrm{mM} \mathrm{NaCl}$ using a Superdex 75 analytical column, in conditions described in the supplemental. 
Molecular markers (cytochrome c, 12400 Da; P105G Dd-NDPK, monomeric version from Dictyostelium discoideum, $16800 \mathrm{Da}$; myoglobin, $17000 \mathrm{Da}$; carbonic anhydrase, $29000 \mathrm{Da}$; ovalbumin, 44000 Da; BSA, 68000 Da; aldolase, 158000 Da) from GE Healthcare Life Sciences were used. The P105G Dd-NDPK, monomeric version from Dictyostelium discoideum, was a gift from Pr. Ioan Lascu and has an elution volume of $12.6 \mathrm{~mL}$ (data not shown).

NDPK enzymatic activity was measured using a coupled assay. ${ }^{(52,53)}$ The reactions of the test are shown below and the enzymes catalyzing each reaction are indicated in parentheses. In this assay, NDPK catalyzes phosphate transfer from ATP to 8-bromoinosine-5'-diphosphate (8-BrIDP). The enzyme mix contained in a final volume of $0.8 \mathrm{~mL}: 20 \mathrm{mM}$ Tris- $\mathrm{HCl}(\mathrm{pH} 7.5), 5 \mathrm{mM} \mathrm{MgCl}$, $100 \mathrm{mM} \mathrm{KCl}, 1 \mathrm{mg} / \mathrm{mL}$ BSA, $1 \mathrm{mM}$ de phosphoenol pyruvate, $0.1 \mathrm{mM}$ NADH, $1 \mathrm{mM}$ ATP, 0.2 $\mathrm{mM}$ 8-BrIDP, $2 \mathrm{U} / \mathrm{mL}$ of pyruvate kinase and lactate dehydrogenase. We measured NADH disappearance at $340 \mathrm{~nm}$ and $25^{\circ} \mathrm{C}$, using a Perkin-Elmer spectrophotometer. For such assay, the errors associated with the kinetic parameters are under $20 \% .^{(32,53)}$

$$
\begin{aligned}
& \mathrm{ATP}+8 \text {-BrIDP } \rightarrow \text { ADP + 8-BrITP } \quad \text { (NDPK) } \\
& \mathrm{ADP}+\mathrm{PEP} \rightarrow \mathrm{ATP}+\text { pyruvate } \quad \text { (pyruvate kinase) } \\
& \text { pyruvate }+\mathrm{NADH} \rightarrow \text { lactate }+\mathrm{NAD}^{+} \quad \text { (lactate dehydrogenase) }
\end{aligned}
$$

Unfolding and refolding. The unfolding/refolding experiments were performed as previously described. ${ }^{(53)} 10 \mu \mathrm{g} / \mathrm{mL}$ final concentration of native or unfolded $M t$-NDPK were incubated for $16 \mathrm{~h}$ in 0-8 $\mathrm{M}$ urea or $0-5 \mathrm{M} \mathrm{GuHCl}$, and $20 \mathrm{mM}$ phosphate buffer, $\mathrm{pH} 7.0$ at $25^{\circ} \mathrm{C}$. Fluorescence intensities of the single tryptophan residue Trp132 were measured at $335 \mathrm{~nm}$ with an excitation at $295 \mathrm{~nm}$.

Continuous HDX. Experiments were performed at full length and peptide resolution, by following the schemes (Figures 2A and S2A). Stock solutions of $2.0 \mu \mathrm{M}$ native $M t$-NDPKs (WT and D93N) were prepared in $20 \mathrm{mM}$ Tris- $\mathrm{HCl} \mathrm{pH} 7.5,100 \mathrm{mM} \mathrm{KCl}, \mathrm{H}_{2} \mathrm{O}$. Deuterium exchange was initiated by dilution of the $M t$-NDPK stock solution 10-fold into $20 \mathrm{mM}$ Tris- $\mathrm{HCl}, 20 \mathrm{mM} \mathrm{KCl}, \mathrm{pD}$ $7.5,99.9 \% \mathrm{D}_{2} \mathrm{O}, 10^{\circ} \mathrm{C}$. The $\mathrm{KCl}$ salt concentration was reduced from $100 \mathrm{mM}$ to $20 \mathrm{mM}$ in order to obtain better MS spectra quality. At different times of incubation, a $200 \mu \mathrm{L}$ aliquot from the exchange reaction was removed (from $10 \mathrm{~s}$ to $90 \mathrm{~min}$ ) and labeling was quenched by adjusting the $\mathrm{pH}$ to 2.5 with formic acid, at $0^{\circ} \mathrm{C}$. 


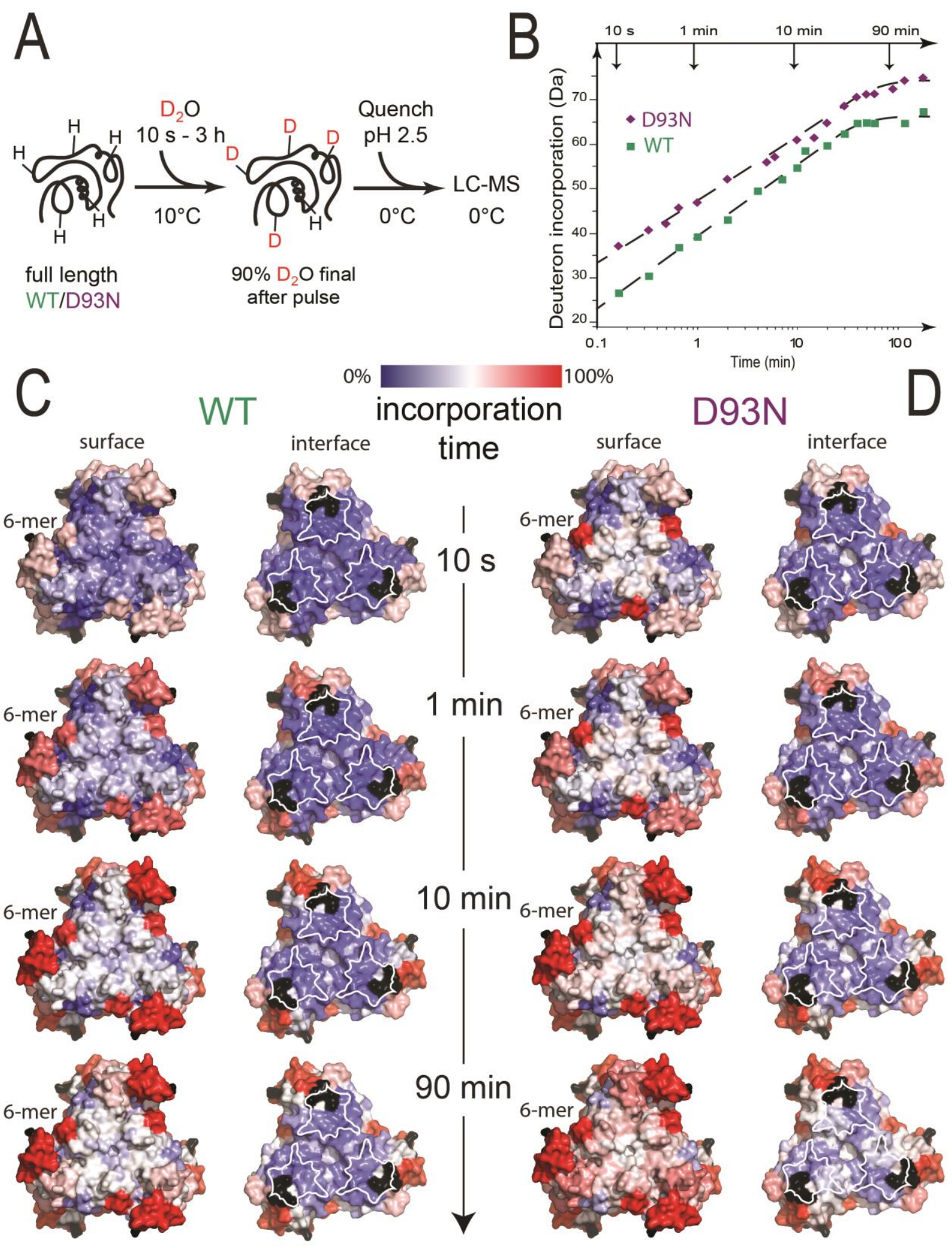

FIGURE 2 
For full length experiments, protein samples were immediately injected into an Alltech analytical guard column, packed with POROS 20-R1 reversed-phase media (PerSeptive Biosystems). Each sample was washed within $20 \mathrm{~s}$ with $400 \mu \mathrm{L}$ of $0.1 \%$ formic acid, ice cold. The guard column was then switched in line with the HPLC inject port with a flow rate of $200 \mu \mathrm{L} / \mathrm{min}$ of $15 \%$ acetonitrile/ $0.1 \%$ formic acid, $\mathrm{pH} 2.5$ for $2 \mathrm{~min}$. The protein was eluted at $40 \mu \mathrm{L} / \mathrm{min}$ using a 1.5 min gradient of 15\%-75\% acetonitrile directly into a Waters Synapt G1 mass spectrometer with a standard electrospray interface. The injector, column and all associated tubings were kept at $0^{\circ} \mathrm{C}$ using an ice bath to minimize back exchange. ${ }^{(58)}$ All experiments were conducted under identical conditions to allow comparison of relative deuterium levels. ${ }^{(9)}$ Mass accuracy of less than 20 ppm was maintained by infusing horse heart myoglobin into the mass spectrometer at the end of each chromatographic gradient. Intact mass spectra were deconvoluted using MassLynx (Waters) and masses were corrected for back exchange (17\%) and dilution effect (10\%). As controls, unfolded and native $M t$-NDPKs were subjected to $\mathrm{D}_{2} \mathrm{O}$ pulse labeling and LC-MS analysis. The backexchange of $17 \%$ was measured by diluting denatured $M t$-NDPKs ( $6 \mathrm{M} \mathrm{GuDCl}, 1 \mathrm{mM}$ DTT) into $20 \mathrm{mM}$ Tris- $\mathrm{HCl}, 20 \mathrm{mM} \mathrm{KCl}$ buffer prepared with $99.9 \mathrm{D}_{2} \mathrm{O}$. After $10 \mathrm{~s}$ of deuteration, the reaction was quenched and immediately subjected to LC-MS at $0^{\circ} \mathrm{C}$.

To obtain HDX data at peptide resolution, $200 \mu \mathrm{L}$ of each acid-quenched sample were injected into a loop of $100 \mu \mathrm{L}$ inside an HDX Waters nanoACQUITY Ultra Performance Liquid Chromatography (UPLC). ${ }^{(58)}$ The sample passed through a Poroszyme-immobilized pepsin cartridge (Applied Biosystems) accommodated within the HDX manager at a flow rate of $100 \mu \mathrm{L}$ $\min ^{-1}$ and temperature of $20^{\circ} \mathrm{C}$. Peptic peptides eluting from the pepsin column were trapped and desalted for $3 \mathrm{~min}$ at $100 \mu \mathrm{L} \mathrm{min}{ }^{-1}$, and then separated in 7 min with $8 \%$ to $40 \%$ acetonitrile:water gradient at $40 \mu \mathrm{L} \mathrm{min}{ }^{-1}$, all steps were carried out in $0.1 \%$ formic acid $\mathrm{pH} 2.5$ before MS analysis. The separation column was a 1.0×100.0 mm ACQUITY UPLC C18 BEH (Waters) containing 1.7 $\mu \mathrm{m}$ particles and the back pressure averaged 8000 psi. All chromatographic elements were held at $0^{\circ} \mathrm{C}$ for the entire time of the measurements. The average amount of back exchange was around $25 \%$ based on analysis of highly deuterated peptide standards. ${ }^{(58)}$ Deuterium levels were corrected for $25 \%$ back-exchange and $10 \%$ dilution, all comparison experiments being done under identical experimental conditions. The UPLC steps were performed with protonated solvents, thereby allowing deuterium to be replaced with hydrogen from side chains and the amino/carboxyl terminus that exchange much faster than amide linkages. ${ }^{(5,9)}$ The error in the determination of the deuterium levels was $\pm 0.20 \mathrm{Da}$ in this experimental setup consistent with previously obtained values. ${ }^{(17,23,59)}$ 
Mass spectra were obtained with a Waters Synapt G1 using a standard ESI source (Waters Corp., Milford, MA, USA) over an m/z range of 50-1700. Mass accuracy was ensured by calibration with Glu-fibrinogen peptide, and was less than 10 ppm throughout all experiments. Identification of the peptic fragments was accomplished with at least 4 replicate $\mathrm{MS}^{\mathrm{E}}$ analyses ${ }^{(23)}$ using Identity Software (Waters Corp., Milford, MA, USA). $\mathrm{MS}^{\mathrm{E}}$ was performed by realizing series of low-high collision energies ramping from 5-30 V, therefore ensuring proper fragmentation of all the peptic peptides eluting from the LC system.

Pulse HDX. To characterize the unfolding pathway of D93N, the purified protein was first pre-incubated at $2 \mu \mathrm{M}$ in $0-8 \mathrm{M}$ urea, for $16 \mathrm{~h}$ at $10^{\circ} \mathrm{C}$. After this step, the pulse labeling experiment was performed following the scheme (Figure S3C). $20 \mu \mathrm{L}$ of each sample were deuterated for $12 \mathrm{~s}$ by dilution of the protein stock solution 10-fold into $20 \mathrm{mM}$ Tris- $\mathrm{HCl}, 20 \mathrm{mM} \mathrm{KCl}$, pD 7.5, 99.9\% $\mathrm{D}_{2} \mathrm{O}$, at $10^{\circ} \mathrm{C}$. Deuteration was stopped by quenching the reaction with formic acid, final $\mathrm{pH}$ at 2.5 , at $0^{\circ} \mathrm{C}$. After the quenching step, samples were digested or not and analyzed as described in the previous paragraph concerning the continuous labeling.

The unfolding pathway of the WT was characterized in the same way as for the D93N one, except that we used a higher performance mass spectrometer (Synapt G2 Si, Waters) allowing a 9fold lower working protein concentration. Pre-incubation of WT was performed at about $220 \mathrm{nM}$ final and the pulse labeling experiment followed the scheme (Figure S3C), all the other experimental aspects were identical to the ones explained for unfolding of D93N.

Spontaneous refolding of WT $M t$-NDPK was initiated by 400 -fold dilution from $7.2 \mathrm{M} \mathrm{GuHCl}$ into refolding buffer $(20 \mathrm{mM}$ Tris- $\mathrm{HCl}, \mathrm{pH} 7.5,100 \mathrm{mM} \mathrm{KCl})$ at $10^{\circ} \mathrm{C}$ and final protein concentration of $220 \mathrm{nM}$. Residual $\mathrm{GuHCl}$ concentration was as low as $18 \mathrm{mM}$ in order to not disturb the refolding process. The reaction scheme shown in Figure S4A was followed. Aliquots of refolded $M t$-NDPK were deuterated for 12 seconds, quenched with formic acid at $\mathrm{pH} 2.5$ and analyzed as described above for the continuous labeling experiments. A Synapt G2 Si mass spectrometer was used for these experiments. The unfolded references were arbitrarily given a refolding time of $3 \mathrm{~s}$ in these graphs.

Peptide Mass Analysis and Data Processing. Mass spectra were processed using DynamX 2.0 software (Waters) by centroiding the isotopic distribution corresponding to all charge states of each peptide. Automated selection of the isotope distribution was verified manually for all peptides 
and all charge states. The resulting relative deuterium levels (corrected for $25 \%$ back exchange and $10 \%$ dilution factor) were plotted versus the exchange-in time with respect to experimental described conditions. All comparison experiments were done under identical experimental conditions. NDPKs unfolded during $1 \mathrm{~h}$ in GuDCl $6 \mathrm{M}$ were used as controls for $100 \%$ deuterated protein. The error of determining the deuterium levels was $\pm 0.20 \mathrm{Da}$ for the experimental setup used. $^{(17,23,59)}$ For the pulse labeling experiments, when the isotope distributions were bimodal, all isotopes of the entire bimodal pattern were selected for processing. ${ }^{(23)}$ The relative deuterium incorporation was calculated by subtracting the centroid of the isotopic distribution for peptide ions of the native reference from the centroid of the isotopic distribution for peptide ions from each refolding sample (Figure S4B). All molecular structure figures were prepared using PyMol, ${ }^{(60)}$ and the alignment figure using ESPript (http://espript.ibcp.fr). ${ }^{(61)}$

\section{RESULTS AND DISCUSSION}

\section{Impact of destabilizing D93N mutation on $M t$-NDPK hexamer dynamics}

Here we perform continuous labeling HDX coupled to liquid chromatography (LC) and mass spectrometry (MS) to characterize the overall conformational dynamics of purified hexameric WT and D93N $M t$-NDPKs (Figure 2A). Samples kept at $10^{\circ} \mathrm{C}$ are incubated for $10 \mathrm{~s}$ to 90 min into $90 \%$ $\mathrm{D}_{2} \mathrm{O}$ final concentration and acid quenched on ice to stop the H/D exchange. On line injection of full length protein to a LC-MS system allows immediate mass measurement. Deuterium incorporation in WT and D93N hexamers follows apparent first-order exponential kinetics from 10 $\mathrm{s}$ to 40 and 60 min respectively, when two maximum values are reached (Figure 2B). These values of 67 and 75 D's (after correction for back exchange (17\%) and dilution effect (10\%)), on 129 theoretically accessible H's, show that more than half of each chain is solvent accessible. At each incubation time, WT incorporates between 5 and 11 D's less than D93N indicating a higher overall rigidity for WT. The WT is thermodynamically more stable than the D93N mutant, clearly supporting the view that increased stability reduces flexibility. ${ }^{(3)}$

To gain spatial information, we next performed continuous labeling HDX-MS at peptide level resolution by adding a pepsin digestion step before LC-MS (Figure S2A). 27 identical polypeptides covering $95.6 \%$ of the sequence were analyzed in both proteins (Figure S2B). 17 peptides had identical or almost identical behavior while 10 overlapping peptides (gray shaded panels) covering $27 \%$ of the total sequence, start and end with different exchange levels of at least $0.50 \mathrm{Da}$, 
representing more than $15 \%$ when normalized to the maximal incorporation value (Figure S2C). The highest flexibility is noticed in both hexamers for surface regions 39-62 (hairpin $\alpha_{A} / \alpha_{2}$ ), 108113 (helix $\alpha 3^{\prime}$ '), and 132-136 (C-term end), which interestingly correspond to the most divergent sequences in NDPKs (Figures 2C-D, S2D). For the C-terminal end, the deuteration is already maximal at the first experimental time point after $10 \mathrm{~s}$, as indicated by the corresponding flat plots. Because of its biological relevance, original search for flexible regions in NDPKs started two decades ago using ${ }^{1} \mathrm{H}$ NMR. ${ }^{(62)}$ Here, our HDX-MS results show that as previously suggested, ${ }^{(50,62)}$ the hairpin $\alpha_{A} / \alpha_{2}$ which is a part of the nucleotide binding site, is highly flexible and could undergo large movement in order to accommodate DNA, explaining the DNA binding function. ${ }^{(55)}$ Both WT and D93N hexamers present with full deuteration after $10 \mathrm{~min}$, with three quarters of their sequence being already deuterated at $10 \mathrm{~s}$. The regions specifically affected by the D93N mutation are contiguously located at the hexamer surface (9-15: helix $\left.\alpha_{0}\right)$ and at the trimer interface (85-113: Kpn-loop) (Figures 2C-D, left columns showing the surface). The region 108-113 is fully solvent accessible in the mutant, while in WT it becomes fully deuterated after 3 min exposure to solvent. The peptides covering region 114-130 present about 1 Da difference in deuterium incorporation, which corresponds to less than $15 \%$ difference indicating that mutation did not substantially affect this part of the structure. The strand $\beta_{2}(32-38)$ and the helix $\alpha_{1}(18-27)$, which form the dimer interface, remain inaccessible to solvent indicating high stability for dimers (Figure 2D, right column showing the interface). In conclusion, differences in dynamics for D93N and WT MtNDPK hexamers correlate only with their difference in stability, while their 3D structures are very

similar with an RMSD of $0.23 \AA$. Importantly, the decrease of thermostability of D93N is accompanied by the increase of the conformational flexibility at the hexamer surface, without affecting the stable core of the protein (Figure S2D).

\section{D93N and WT unfolding pathways comparison}

The next questions we addressed were whether the conformational flexibility of NDPK varies with the oligomeric state and whether this potential variation is the reason why oligomerization is required to support function. To find sub-hexameric species, unfolding and refolding pathways of WT and D93N were analyzed in the presence of urea. First, enzyme activity was measured after incubation of native and unfolded NDPK for $16 \mathrm{~h}$ in 0 to $7.2 \mathrm{M}$ urea (Figure S3A). In both cases a hysteresis phenomenon was observed, since unfolding and refolding curves did not overlap, indicating that WT and D93N proteins were not at equilibrium. Second, the hydrodynamic radii of 
NDPK were measured by SEC in 0 to $7.2 \mathrm{M}$ urea, after the same unfolding/refolding procedure (Figure S3B). Again, a hysteresis phenomenon was observed, since for the same urea concentration, the elution volume of NDPK differed between folding and unfolding. Taken together, these results show an absence of equilibrium for WT and D93N during unfolding/folding experiments. They are in full agreement with our previous data on $M t$-NDPK as well as with other similar studies on NDPK which show hysteresis after about 1 day of unfolding/refolding in presence of denaturing agents. $^{(42,53)}$

Having established that unfolding and refolding pathways were different for both WT and D93N NDPKs, we next characterized the potential sub-hexameric species formed during unfolding. WT hexamers were incubated in 0 to $7.2 \mathrm{M}$ urea during 16 hours and the oligomeric state was established by SEC for the different urea concentrations (Figure S3B). Two elution volumes of 9.65 and $10.2 \mathrm{~mL}$ were noticed, indicating respectively a direct passage from native hexamers (0 to 4.0 $\mathrm{M}$ urea) to unfolded monomers ( $>4 \mathrm{M}$ urea). The WT unfolding pathway was next characterized by enzyme activity, which reflects integrality of quaternary structure and by the fluorescence of the unique tryptophan (W132), which reflects integrity of tertiary structure. Both curves overlapped, indicating again concomitant dissociation and unfolding (Figure 3B). 


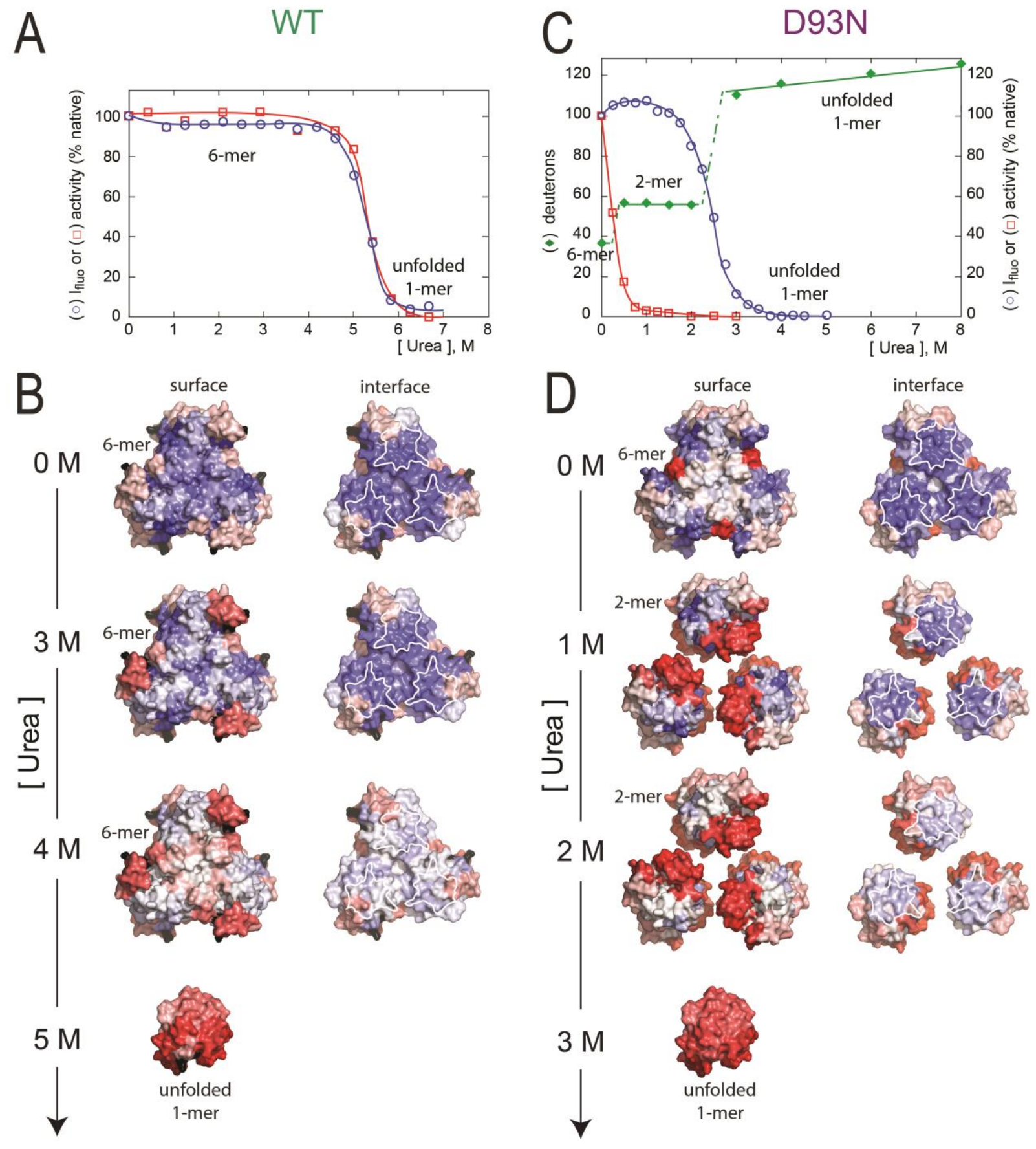

FIGURE 3

To obtain mechanistic details, pulse labeling HDX-MS at the peptide level was performed, following the scheme described in (Figure S3C). The level of deuterium which is detected in the peptides is a signature of the NDPK conformations during unfolding, providing a snapshot of the different coexisting populations. The 31 peptides analyzed, covering $98.5 \%$ of the sequence (Figure 
S2B), all showed bimodal behavior with one transition between the folded/assembled hexamers and unfolded monomers around 4.5 $\mathrm{M}$ urea (Figure S3D). Two representative peptides are shown in Figure 4 (left panels). This result clearly shows concomitant dissociation and unfolding of WT hexamers (Figure 3B), in full agreement with SEC, tryptophan fluorescence and activity data.
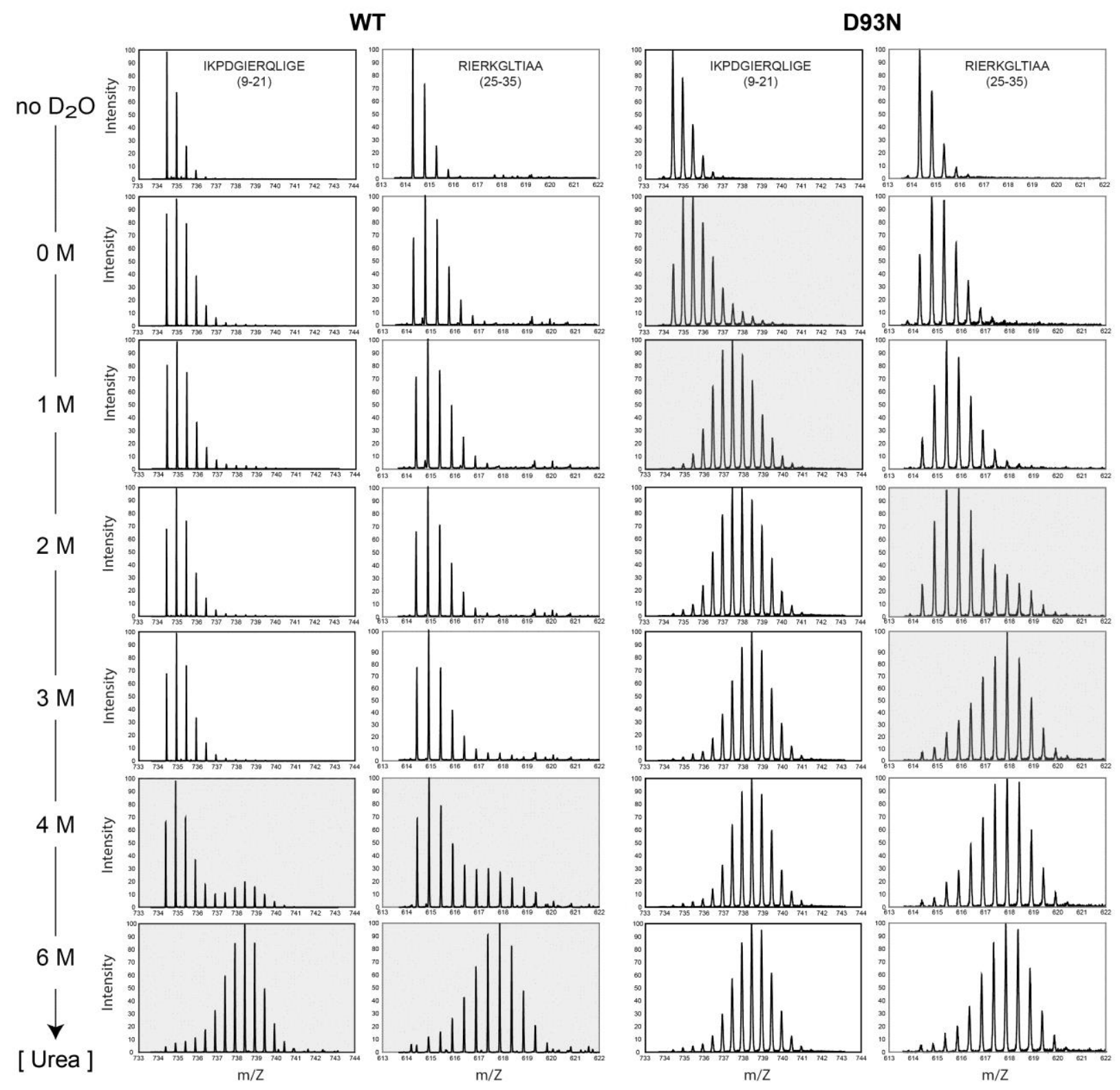

FIGURE 4

When the same strategy of characterization by SEC, enzyme activity and tryptophan fluorescence, followed by HDX-MS analysis was applied to the D93N mutant, a different unfolding 
pathway was highlighted. By SEC, in addition to hexamers and unfolded monomers, a new species was detected at low denaturant concentrations ( 1 and $2 \mathrm{M}$ urea). The column calibration indicates that the elution volume of $11.7 \mathrm{~mL}$ corresponds to native dimers (Figure S3B). At $4 \mathrm{M}$ or higher urea concentrations, this species disappears and only one new peak corresponding to unfolded monomers appears $(10.2 \mathrm{~mL})$, indicating that dimers dissociate and unfold concomitantly. Confirmation of this unfolding pathway was obtained using two additional methods: enzyme activity is lost for urea concentrations higher that $0.5 \mathrm{M}$ (Figure 3C, empty red squares), while from Trp fluorescence, only one transition between native and unfolded species was observed around 2.7 M urea (Figure 3C, empty blue circles). Taken together, these results indicate that D93N hexamers disassemble into dimers before further concomitant dissociation and unfolding into monomers. Pulse labeling HDX-MS at full-length protein level was performed to further characterization. In the absence of urea, hexameric full length D93N incorporates $36 \mathrm{D}$, while between 0.5 and $2.0 \mathrm{M}$ urea, dimers incorporate additional $19 \mathrm{D}$ (Figure 3C, green diamonds). From 3 to $8 \mathrm{M}$ urea, progressive incorporation from 111 to $125 \mathrm{D}$ over the 129 available amide protons reveals monomers with a slightly different level of unfolding, in agreement with SEC, fluorescence and activity data (Figure 3C).

To structurally determine why such dimers are enzymatically inactive, the D93N unfolding pathway was characterized by pulse labeling HDX-MS at peptide level, as described in the scheme of Figure S3C. 30 peptides covering 100\% of the sequence (Figure S2C) were analyzed (Figures 3D, S3E-F). All spectra show bimodal isotope distribution, which corresponds to native or fully unfolded peptide, except peptides 108-113 and 132-136, which are permanently unfolded. Bimodal peptides had transitions between their folded and unfolded states at the same urea concentrations as the ones noticed for the loss of activity $(0.5 \mathrm{M})$ or tertiary structure $(2.7 \mathrm{M})$. The specific behavior of these two categories of peptide is illustrated by their mass spectra of peptides 9-21 and 25-35, respectively (Figure 4, right panels). Remarkably, at $0.5 \mathrm{M}$ urea, the loss of enzyme activity is due to unfolding of the regions 85-107 (Kpn-loop) at the trimer interface and 9-16 (helix $\alpha_{0}$ ). These regions are far in the sequence but close in the structure and constitute a separate subdomain of the rest of the monomer, further called $K p n / \alpha_{0}$ subdomain. The rest of the sequence including the dimer interface (region 17-40: helix $\alpha_{1}$, and strand $\beta_{2}$ ) is not altered up to urea concentrations higher than 2.7 M, when the dimers simultaneously dissociate and unfold. Taken together, these data show that the D93N inactive intermediate species correspond to native-like folded dimers, instead of 
monomers, as previously proposed. ${ }^{(53)}$ These dimers are well folded except for the $K p n / \alpha_{0}$ subdomain which is fully solvent accessible and by consequence lacks stable structure.

WT and D93N hexamers exhibit similar enzyme properties but different thermodynamic stabilities, which are responsible for their different unfolding pathways (Figure S3G). WT hexamers dissociate and unfold concomitantly indicating high cooperativity between all six subunits. D93N hexamers first dissociate into dimers before further concomitant dissociation and unfolding, indicating a partial loss of cooperativity between subunits, and so demonstrate the important role played by ionic bonds for cooperativity inside complexes. D93N dimers are inactive and much less stable compared to WT-hexamers (Figures 3A and 3C, blue curves). Importantly, the lack of activity is only due to the lack of stable structure of the $K p n / \alpha_{0}$ subdomain, indicating that even a single-domain protein can have its dynamics uncoupled between its structural subdomains.

\section{Characterization of refolding and assembly pathway of WT $M t$-NDPK}

Stable but inactive species accumulate for WT $M t$-NDPK only during refolding at low protein concentration (Figure 5A, blue circles), ${ }^{(53)}$ and their characterization by size exclusion chromatography indicates they are dimers (Figure S3B). 


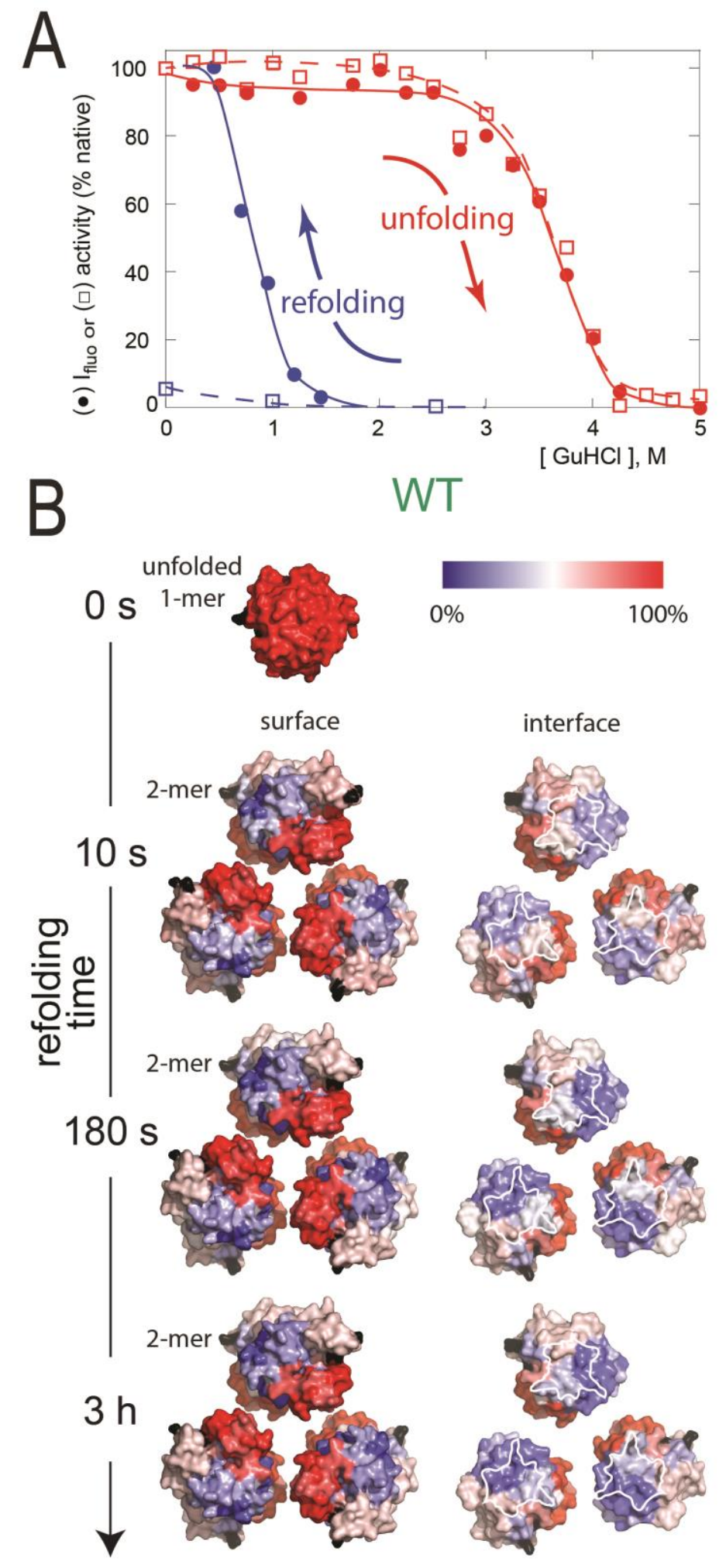

FIGURE 5 
Next, we took advantage of the HDX-MS sensitivity to analyze the WT refolding and assembly pathway at peptide resolution. Unfolded WT protein in $7.2 \mathrm{M} \mathrm{GuHCl}$ final concentration was diluted 400-fold into refolding buffer to a final concentration of $220 \mathrm{nM}$ for $0-3 \mathrm{~h}$. Aliquots were deuterated, quenched and digested, and the peptide masses were immediately measured (Figure $\mathrm{S} 4 \mathrm{~A}$ ). It is important to note that the residual $18 \mathrm{mM} \mathrm{GuHCl}$ in the refolding buffer is insufficient to unfold any peptide and did not affect the folding/assembly pathway. Strikingly, after 10-30 seconds refolding, all peptides became native, except for the previously described $K p n / \alpha_{0}$ subdomain (84107 and 9-21), which stays fully unfolded during at least $3 \mathrm{~h}$ (Figure S4B). The weak hydrophobicity of the $K p n / \alpha_{0}$ subdomain, when compared to the rest of the NDPK sequence, is probably not sufficient to allow its burying/folding by hydrophobic collapse. We conclude that, in agreement with stopped-flow data, ${ }^{(53)}$ WT monomers are rapidly folded and assembled into inactive dimers (Figures 5B, S4C) similar to the ones described for D93N unfolding. WT and D93N dimers are native-like except for the $K p n / \alpha_{0}$ subdomain, which gets buried and structured only during assembly into hexamers, inducing enzyme activation.

During two decades and based on spectroscopic methods, it has been proposed that structurally single-domain proteins - like NDPKs - present only two conformations (folded or unfolded), the interconversion between them being performed within one single step, without formation of stable intermediates. ${ }^{(63)}$ Here we show that such methods are insufficient to fully characterize properties of folding/unfolding intermediates, mostly when such intermediates present many but not all physical properties the native protein possess. We propose that as for a few proteins, ${ }^{(64)} M t$-NDPK folding/unfolding appears by blocks or subdomains, which are called foldons in the literature. ${ }^{(63)}$ Clearly in our study the $K p n / \alpha_{0}$ subdomain is indeed such a foldon. We could demonstrate that the $K p n / \alpha_{0}$ foldon is unstructured in monomers/dimers and acquires stable conformation only upon full hexameric assembly. Since the $K p n / \alpha_{0}$ foldon is part of the catalytic site, this explains why full hexamerisation is required for enzyme function acquisition. Finally, our study demonstrates that during the phenomena of folding/unfolding of NDPK, the $K p n / \alpha_{0}$ foldon is stabilized/destabilized in a cooperative sequential order.

\section{CONCLUSIONS}

In this study we have applied a combination of biochemical and biophysical methods to $M t$ NDPK including the emerging technique of structural mass spectrometry to investigate the link between a protein's function and several of its physical parameters: conformational dynamics, 
stability and oligomerization. Even though NDPK research today comprises more than 2500 publications, the HDX-MS methodology has only marginally been applied to study this important class of proteins. ${ }^{(65)}$ Here, for the first time, its application provides an explanation of why oligomerization is required for the kinase function. We show that in order to be active, hexameric NDPK requires a structured $K p n / \alpha_{0}$ foldon, while to be structured the foldon requires the assembly of the NDPK. NDPKs are oligomeric enzymes devoid of allosteric regulation. Many structures of NDPKs have been solved in the presence of different ligands (ADP, non hydrolysable ATP analogues, small molecules, ...), but the apo and in complex structures are identical and do not show conformational changes. Here, we show that the $K p n / \alpha_{0}$ foldon is an activation region and a critical control switch, through its shifting between the structured or unstructured conformation.

Since not all NDPKs are hexameric, the question arises as to how bacterial tetrameric and dimeric ones are active. The analysis of crystal structures shows that in the type 2 tetramer, ${ }^{(46)}$ the $K p n / \alpha_{0}$ foldon is located at the dimer-dimer interface and has the same control switch role. On the contrary, in type 1 tetramer $^{(66)}$ and dimer, ${ }^{(47,67,68)}$ the $K p n / \alpha_{0}$ foldon is fully exposed and could not have such a regulatory role. High eukaryotes have several isoforms of NDPK with additional functions: metastasis suppression in humans ${ }^{(35,36,69,70)}$ and involvement in animal development. ${ }^{(71-}$ 73) Interestingly, natural mutants for these two hexameric NDPKs present folding or assembly defects. ${ }^{(72)}$ Since our present study on $M t$-NDPK shows that flexibility is increased by the hexamer's destabilization, we suggest these mutants are inactive because of aberrant conformational dynamics. Potentially, their stabilization could be enhanced by rational design of their most dynamic parts, a promising but actually unexplored strategy in cancer or developmental research. In conclusion, our results illustrate the power of MS-based technologies to uncover new concepts in studying structure-activity relationships, in complement to biochemical techniques, X-ray crystallography and NMR.

\section{ASSOCIATED INFORMATION}

Sequence of Mt-NDPK (136 aa) with the secondary structure elements, the Kpn-loop, the active site residues, the inter-subunit salt bridge, the solvent accessibility of each residue (Figure S1A), scheme of continuous labeling HDX-MS experiment at peptide level (Figure S2A), peptide maps (Fig S2B), kinetics of deuterium incorporation for peptic peptides of WT and D93N (Figure S2C), local dynamics of WT and D93N (Fig S2D), unfolding and refolding of WT and D93N followed by activity (Figure S3A) and size-exclusion chromatography (Figure S3B), scheme of the pulse 
labeling HDX-MS experiment for the D93N and WT after incubation in urea (Figure S3C), deuterium incorporation for peptic peptides of WT (Figure S3D) and D93N (Figure S3E), pulse labeling HDX data for D93N in 0 and $1 \mathrm{M}$ urea mapped onto the WT structure (Figure S3F), pulsed labeling HDX-MS data for WT and D93N in 0-6 M urea were mapped onto the monomer WT structure (Figure S3G), scheme of the refolding/assembly experiment followed by pulsed labeling HDX-MS at peptide level (Figure S4A), kinetics of deuterium incorporation for peptic peptides of WT (Figure S4B), pulsed labeling HDX-MS data for refolding and assembly pathway of WT mapped onto the monomer WT structure.

\section{ACKNOWLEDGEMENTS}

The authors wish to thank Pr Anna Giartosio, Pr Ioan Lascu, Dr Erin Henninger and the European Synchrotron Radiation Facility (ESRF, Grenoble, France). This work was supported by the Fondation ARC pour la Recherche sur le Cancer (FR) to F.G and P.M (Grant SFI20101201793) and by Agence Nationale de la Recherche to A.D. (Grant ANR-12-BSV8-024) and P.M. (Grant ANR-11-BSV8-015-03 and ANR-16-CE11-0032). P.M. was supported by the LABEX DYNAMO (Grant ANR-11-LABX-0011) and EQUIPEX CACSICE (ANR-11-EQPX-0008CACSICE).

Keywords: structure-activity relationship $\cdot$ protein folding $\cdot$ hydrogen deuterium exchange mass spectrometry $\cdot$ nucleoside diphosphate kinase $\cdot$ oligomerization 


\section{REFERENCES}

1. Nishi, H., Hashimoto, K., Madej, T., and Panchenko, A. R. (2013) Evolutionary, physicochemical, and functional mechanisms of protein homooligomerization. Prog. Mol. Biol. Transl. Sci. 117, 3-24.

2. Marsh, J. A., and Teichmann, S. A. (2015) Structure, dynamics, assembly, and evolution of protein complexes. Annu. Rev. Biochem. 84, 551-575.

3. Karshikoff, A., Nilsson, L., and Ladenstein, R. (2015) Rigidity versus flexibility: The dilemma of understanding protein thermal stability. FEBS J. 282, 3899-3917.

4. Teilum, K., Olsen, J. G., and Kragelund, B. B. (2011) Protein stability, flexibility and function. Biochim. Biophys. Acta 1814, 969-976.

5. Engen, J. R. (2009) Analysis of protein conformation and dynamics by hydrogen/deuterium exchange ms. Anal. Chem. 81, 7870-7875.

6. Lossl, P., van de Waterbeemd, M., and Heck, A. J. (2016) The diverse and expanding role of mass spectrometry in structural and molecular biology. EMBO J. 35, 2634-2657.

7. Marcoux, J., and Cianferani, S. (2015) Towards integrative structural mass spectrometry: Benefits from hybrid approaches. Methods 89, 4-12.

8. Mehmood, S., Allison, T. M., and Robinson, C. V. (2015) Mass spectrometry of protein complexes: From origins to applications. Annu. Rev. Phys. Chem. 66, 453-474.

9. Wales, T. E., and Engen, J. R. (2006) Hydrogen exchange mass spectrometry for the analysis of protein dynamics. Mass Spectrom. Rev. 25, 158-170.

10. Engen, J. R., and Wales, T. E. (2015) Analytical aspects of hydrogen exchange mass spectrometry. Annu. Rev. Anal. Chem. 8, 127-148.

11. Pirrone, G. F., Iacob, R. E., and Engen, J. R. (2015) Applications of hydrogen/deuterium exchange ms from 2012 to 2014. Anal. Chem. 87, 99-118.

12. Konermann, L., Vahidi, S., and Sowole, M. A. (2014) Mass spectrometry methods for studying structure and dynamics of biological macromolecules. Anal. Chem. 86, 213-232.

13. Guttman, M., and Lee, K. K. (2016) Isotope labeling of biomolecules: Structural analysis of viruses by hdx-ms. Methods Enzymol. 566, 405-426.

14. Marciano, D. P., Dharmarajan, V., and Griffin, P. R. (2014) Hdx-ms guided drug discovery: Small molecules and biopharmaceuticals. Curr. Opin. Struct. Biol. 28, 105-111.

15. Leurs, U., Mistarz, U. H., and Rand, K. D. (2015) Getting to the core of protein pharmaceuticals--comprehensive structure analysis by mass spectrometry. Eur. J. Pharm. Biopharm. 93, 95-109. 
16. Engen, J. R., Wales, T. E., Chen, S., Marzluff, E. M., Hassell, K. M., Weis, D. D., and Smithgall, T. E. (2013) Partial cooperative unfolding in proteins as observed by hydrogen exchange mass spectrometry. Int. Rev. Phys. Chem. 32, 96-127.

17. Iacob, R. E., Pene-Dumitrescu, T., Zhang, J., Gray, N. S., Smithgall, T. E., and Engen, J. R. (2009) Conformational disturbance in abl kinase upon mutation and deregulation. Proc. Natl. Acad. Sci. USA 106, 1386-1391.

18. Edgeworth, M. J., Phillips, J. J., Lowe, D. C., Kippen, A. D., Higazi, D. R., and Scrivens, J. H. (2015) Global and local conformation of human igg antibody variants rationalizes loss of thermodynamic stability. Angew. Chem. 54, 15156-15159.

19. Roberts, J. M., Tarafdar, S., Joseph, R. E., Andreotti, A. H., Smithgall, T. E., Engen, J. R., and Wales, T. E. (2016) Dynamics of the tec-family tyrosine kinase sh3 domains. Protein Sci. 25, 852-864.

20. Wales, T. E., Poe, J. A., Emert-Sedlak, L., Morgan, C. R., Smithgall, T. E., and Engen, J. R. (2016) Hydrogen exchange mass spectrometry of related proteins with divergent sequences: A comparative study of hiv-1 nef allelic variants. J. Am. Soc. Mass Spectrom. 27, 10481061.

21. Das, M., Wilson, C. J., Mei, X., Wales, T. E., Engen, J. R., and Gursky, O. (2016) Structural stability and local dynamics in disease-causing mutants of human apolipoprotein a-i: What makes the protein amyloidogenic? J. Mol. Biol. 428, 449-462.

22. Hodkinson, J. P., Radford, S. E., and Ashcroft, A. E. (2012) The role of conformational flexibility in beta2-microglobulin amyloid fibril formation at neutral ph. Rapid Commun. Mass Spectrom. 26, 1783-1792.

23. Georgescauld, F., Popova, K., Gupta, A. J., Bracher, A., Engen, J. R., Hayer-Hartl, M., and Hartl, F. U. (2014) Groel/es chaperonin modulates the mechanism and accelerates the rate of tim-barrel domain folding. Cell 157, 922-934.

24. Singh, J., and Udgaonkar, J. B. (2015) Structural effects of multiple pathogenic mutations suggest a model for the initiation of misfolding of the prion protein. Angew. Chem. 54, 7529-7533.

25. Huang, R. Y., Garai, K., Frieden, C., and Gross, M. L. (2011) Hydrogen/deuterium exchange and electron-transfer dissociation mass spectrometry determine the interface and dynamics of apolipoprotein e oligomerization. Biochemistry 50, 9273-9282.

26. Wang, H., Shu, Q., Rempel, D. L., Frieden, C., and Gross, M. L. (2015) Continuous and pulsed hydrogen-deuterium exchange and mass spectrometry characterize csge oligomerization. Biochemistry 54, 6475-6481.

27. Monroe, E. B., Kang, S., Kyere, S. K., Li, R., and Prevelige, P. E., Jr. (2010) Hydrogen/deuterium exchange analysis of hiv-1 capsid assembly and maturation. Structure $18,1483-1491$. 
28. Faleri, A., Santini, L., Brier, S., Pansegrau, W., Lo Surdo, P., Scarselli, M., Buricchi, F., Volpini, G., Genovese, A., van der Veen, S., Lea, S., Tang, C. M., Savino, S., Pizza, M., Finco, O., Norais, N., and Masignani, V. (2014) Two cross-reactive monoclonal antibodies recognize overlapping epitopes on neisseria meningitidis factor $\mathrm{h}$ binding protein but have different functional properties. FASEB J. 28, 1644-1653.

29. Malito, E., Faleri, A., Lo Surdo, P., Veggi, D., Maruggi, G., Grassi, E., Cartocci, E., Bertoldi, I., Genovese, A., Santini, L., Romagnoli, G., Borgogni, E., Brier, S., Lo Passo, C., Domina, M., Castellino, F., Felici, F., van der Veen, S., Johnson, S., Lea, S. M., Tang, C. M., Pizza, M., Savino, S., Norais, N., Rappuoli, R., Bottomley, M. J., and Masignani, V. (2013) Defining a protective epitope on factor $\mathrm{h}$ binding protein, a key meningococcal virulence factor and vaccine antigen. Proc. Natl. Acad. Sci. USA 110, 3304-3309.

30. Shi, Y., Chen, X., Elsasser, S., Stocks, B. B., Tian, G., Lee, B. H., Shi, Y., Zhang, N., de Poot, S. A., Tuebing, F., Sun, S., Vannoy, J., Tarasov, S. G., Engen, J. R., Finley, D., and Walters, K. J. (2016) Rpn1 provides adjacent receptor sites for substrate binding and deubiquitination by the proteasome. Science 351.

31. Veesler, D., Khayat, R., Krishnamurthy, S., Snijder, J., Huang, R. K., Heck, A. J., Anand, G. S., and Johnson, J. E. (2014) Architecture of a dsdna viral capsid in complex with its maturation protease. Structure 22, 230-237.

32. Lascu, I., and Gonin, P. (2000) The catalytic mechanism of nucleoside diphosphate kinases. J. Bioenerg. Biomembr. 32, 237-246.

33. Boissan, M., and Lacombe, M. L. (2011) Learning about the functions of nme/nm23: Lessons from knockout mice to silencing strategies. Naunyn-Schmiedeberg's Arch. Pharmacol. 384, 421-431.

34. Steeg, P. S., Zollo, M., and Wieland, T. (2011) A critical evaluation of biochemical activities reported for the nucleoside diphosphate kinase/nm23/awd family proteins: Opportunities and missteps in understanding their biological functions. NaunynSchmiedeberg's Arch. Pharmacol. 384, 331-339.

35. Takacs-Vellai, K. (2014) The metastasis suppressor nm23 as a modulator of ras/erk signaling. J Mol Signal 9, 4.

36. Marino, N., Nakayama, J., Collins, J. W., and Steeg, P. S. (2012) Insights into the biology and prevention of tumor metastasis provided by the nm23 metastasis suppressor gene. Cancer Metastasis Rev. 31, 593-603.

37. Attwood, P. V. (2013) Histidine kinases from bacteria to humans. Biochem. Soc. Trans. 41, $1023-1028$

38. Attwood, P. V., and Wieland, T. (2015) Nucleoside diphosphate kinase as protein histidine kinase. Naunyn-Schmiedeberg's Arch. Pharmacol. 388, 153-160. 
39. Srivastava, S., Panda, S., Li, Z., Fuhs, S. R., Hunter, T., Thiele, D. J., Hubbard, S. R., and Skolnik, E. Y. (2016) Histidine phosphorylation relieves copper inhibition in the mammalian potassium channel kca3.1. eLife 5.

40. Boissan, M., Montagnac, G., Shen, Q., Griparic, L., Guitton, J., Romao, M., Sauvonnet, N., Lagache, T., Lascu, I., Raposo, G., Desbourdes, C., Schlattner, U., Lacombe, M. L., Polo, S., van der Bliek, A. M., Roux, A., and Chavrier, P. (2014) Membrane trafficking. Nucleoside diphosphate kinases fuel dynamin superfamily proteins with gtp for membrane remodeling. Science 344, 1510-1515.

41. Schlattner, U., Tokarska-Schlattner, M., Epand, R. M., Boissan, M., Lacombe, M. L., KleinSeetharaman, J., and Kagan, V. E. (2015) Mitochondrial nm23-h4/ndpk-d: A bifunctional nanoswitch for bioenergetics and lipid signaling. Naunyn-Schmiedeberg's Arch. Pharmacol. $388,271-278$.

42. Lascu, L., Giartosio, A., Ransac, S., and Erent, M. (2000) Quaternary structure of nucleoside diphosphate kinases. J. Bioenerg. Biomembr. 32, 227-236.

43. Kim, Y. I., Park, S., Jeoung, D. I., and Lee, H. (2003) Point mutations affecting the oligomeric structure of $\mathrm{nm} 23$-h1 abrogates its inhibitory activity on colonization and invasion of prostate cancer cells. Biochem. Biophys. Res. Commun. 307, 281-289.

44. Mocan, I., Georgescauld, F., Gonin, P., Thoraval, D., Cervoni, L., Giartosio, A., DabernatArnaud, S., Crouzet, M., Lacombe, M. L., and Lascu, I. (2007) Protein phosphorylation corrects the folding defect of the neuroblastoma (s120g) mutant of human nucleoside diphosphate kinase a/nm23-h1. Biochem. J. 403, 149-156.

45. Janin, J., Dumas, C., Morera, S., Xu, Y., Meyer, P., Chiadmi, M., and Cherfils, J. (2000) Three-dimensional structure of nucleoside diphosphate kinase. J. Bioenerg. Biomembr. 32, 215-225.

46. Moynie, L., Giraud, M. F., Georgescauld, F., Lascu, I., and Dautant, A. (2007) The structure of the escherichia coli nucleoside diphosphate kinase reveals a new quaternary architecture for this enzyme family. Proteins 67, 755-765.

47. Tokunaga, H., Ishibashi, M., Arisaka, F., Arai, S., Kuroki, R., Arakawa, T., and Tokunaga, M. (2008) Residue 134 determines the dimer-tetramer assembly of nucleoside diphosphate kinase from moderately halophilic bacteria. FEBS Lett. 582, 1049-1054.

48. Yonezawa, Y., Izutsu, K., Tokunaga, H., Maeda, H., Arakawa, T., and Tokunaga, M. (2007) Dimeric structure of nucleoside diphosphate kinase from moderately halophilic bacterium: Contrast to the tetrameric pseudomonas counterpart. FEMS Microbiol. Lett. 268, 52-58.

49. Chen, Y., Morera, S., Mocan, J., Lascu, I., and Janin, J. (2002) X-ray structure of mycobacterium tuberculosis nucleoside diphosphate kinase. Proteins 47, 556-557.

50. Karlsson, A., Mesnildrey, S., Xu, Y., Morera, S., Janin, J., and Veron, M. (1996) Nucleoside diphosphate kinase. Investigation of the intersubunit contacts by site-directed mutagenesis and crystallography. J. Biol. Chem. 271, 19928-19934. 
51. Mesnildrey, S., Agou, F., Karlsson, A., Bonne, D. D., and Veron, M. (1998) Coupling between catalysis and oligomeric structure in nucleoside diphosphate kinase. J. Biol. Chem. $273,4436-4442$.

52. Giartosio, A., Erent, M., Cervoni, L., Morera, S., Janin, J., Konrad, M., and Lascu, I. (1996) Thermal stability of hexameric and tetrameric nucleoside diphosphate kinases. Effect of subunit interaction. J. Biol. Chem. 271, 17845-17851.

53. Georgescauld, F., Moynie, L., Habersetzer, J., Cervoni, L., Mocan, I., Borza, T., Harris, P., Dautant, A., and Lascu, I. (2013) Intersubunit ionic interactions stabilize the nucleoside diphosphate kinase of mycobacterium tuberculosis. PloS one 8, e57867.

54. Georgescauld, F., Moynie, L., Habersetzer, J., and Dautant, A. (2014) Structure of mycobacterium tuberculosis nucleoside diphosphate kinase r80n mutant in complex with citrate. Acta Crystallogr. F Struct. Biol. Commun. 70, 40-43.

55. Kumar, P., Verma, A., Saini, A. K., Chopra, P., Chakraborti, P. K., Singh, Y., and Chowdhury, S. (2005) Nucleoside diphosphate kinase from mycobacterium tuberculosis cleaves single strand DNA within the human c-myc promoter in an enzyme-catalyzed reaction. Nucleic Acids Res. 33, 2707-2714.

56. Sun, J., Wang, X., Lau, A., Liao, T. Y., Bucci, C., and Hmama, Z. (2010) Mycobacterial nucleoside diphosphate kinase blocks phagosome maturation in murine raw 264.7 macrophages. PloS one 5, e8769.

57. Ganaie, A. A., Lella, R. K., Solanki, R., and Sharma, C. (2011) Thermostable hexameric form of eis (rv2416c) protein of $\mathrm{m}$. Tuberculosis plays an important role for enhanced intracellular survival within macrophages. PloS one 6, e27590.

58. Wales, T. E., Fadgen, K. E., Gerhardt, G. C., and Engen, J. R. (2008) High-speed and highresolution uplc separation at zero degrees celsius. Anal. Chem. 80, 6815-6820.

59. Houde, D., Berkowitz, S. A., and Engen, J. R. (2011) The utility of hydrogen/deuterium exchange mass spectrometry in biopharmaceutical comparability studies. J. Pharm. Sci. 100, 2071-2086.

60. Schrodinger, LLC. (2015) The pymol molecular graphics system, version 1.8.

61. Robert, X., and Gouet, P. (2014) Deciphering key features in protein structures with the new endscript server. Nucleic Acids Res. 42, W320-324.

62. Xu, Y., Lecroisey, A., Veron, M., Delepierre, M., and Janin, J. (1997) Nmr studies on the flexibility of nucleoside diphosphate kinase. Proteins 28, 150-152.

63. Englander, S. W., Mayne, L., Kan, Z. Y., and Hu, W. (2016) Protein folding-how and why: By hydrogen exchange, fragment separation, and mass spectrometry. Annu Rev Biophys 45, 135-152. 
64. Hu, W., Kan, Z. Y., Mayne, L., and Englander, S. W. (2016) Cytochrome c folds through foldon-dependent native-like intermediates in an ordered pathway. Proc. Natl. Acad. Sci. USA 113, 3809-3814.

65. Kim, M. S., Jeong, J., Jeong, J., Shin, D. H., and Lee, K. J. (2013) Structure of nm23-h1 under oxidative conditions. Acta Crystallogr. Sect. D. Biol. Crystallogr. 69, 669-680.

66. Boissier, F., Georgescauld, F., Moynie, L., Dupuy, J. W., Sarger, C., Podar, M., Lascu, I., Giraud, M. F., and Dautant, A. (2012) An intersubunit disulfide bridge stabilizes the tetrameric nucleoside diphosphate kinase of aquifex aeolicus. Proteins 80, 1658-1668.

67. Arai, S., Yonezawa, Y., Okazaki, N., Matsumoto, F., Tamada, T., Tokunaga, H., Ishibashi, M., Blaber, M., Tokunaga, M., and Kuroki, R. (2012) A structural mechanism for dimeric to tetrameric oligomer conversion in halomonas sp. Nucleoside diphosphate kinase. Protein Sci. 21, 498-510.

68. Yonezawa, Y., Nagayama, A., Tokunaga, H., Ishibashi, M., Arai, S., Kuroki, R., Watanabe, K., Arakawa, T., and Tokunaga, M. (2015) Nucleoside diphosphate kinase from psychrophilic pseudoalteromonas sp. As-131 isolated from antarctic ocean. Protein J. 34, 275-283.

69. Rosengard, A. M., Krutzsch, H. C., Shearn, A., Biggs, J. R., Barker, E., Margulies, I. M., King, C. R., Liotta, L. A., and Steeg, P. S. (1989) Reduced nm23/awd protein in tumour metastasis and aberrant drosophila development. Nature 342, 177-180.

70. Giraud, M. F., Georgescauld, F., Lascu, I., and Dautant, A. (2006) Crystal structures of s120g mutant and wild type of human nucleoside diphosphate kinase a in complex with adp. J. Bioenerg. Biomembr. 38, 261-264.

71. Timmons, L., and Shearn, A. (2000) Role of awd/nucleoside diphosphate kinase in drosophila development. J. Bioenerg. Biomembr. 32, 293-300.

72. Lascu, I., Chaffotte, A., Limbourg-Bouchon, B., and Veron, M. (1992) A pro/ser substitution in nucleoside diphosphate kinase of drosophila melanogaster (mutation killer of prune) affects stability but not catalytic efficiency of the enzyme. J. Biol. Chem. 267, 1277512781.

73. Takacs-Vellai, K., Vellai, T., Farkas, Z., and Mehta, A. (2015) Nucleoside diphosphate kinases (ndpks) in animal development. Cell. Mol. Life Sci. 72, 1447-1462. 


\section{LEGENDS OF FIGURES}

Figure 1. Structure of $M t$-NDPK (A) View of a $M t$-NDPK monomer with labelled secondary structural elements. (B) Side view of a dimer showing the dimer interface (residues 17, 19-21, 2324, 27, 33-38, and 72) and the active site pocket (K10, Y50, R104, N114, H117, S119, E128). (C) Top view of a trimer. At the trimer interface (residues 16, 25, 28-31, 79-80, 83-84, 87-88, 93-96, 98-102, and 105-110) the Kpn/ $\alpha_{0}$ foldon (the Kpn-loop and the $\alpha_{0}$ helix are colored in magenta and pink, respectively), and the R80-D93 salt bridge (sticks) are involved in hexamer assembly. The trimers stack 'head-to-head' and not 'head-to-tail' such that the $K p n / \alpha_{0}$ is exposed on either side of the hexamer. (D) Side view of the surface of the 6-color hexamer $M t$-NDPK. The active site is colored in yellow. In (B) and (C), the chains are colored as in (D).

Figure 2. Overall and local dynamics of WT and D93N $M t$-NDPK. (A) Scheme of full length continuous labeling HDX-MS experiment. (B) Plot of deuterium incorporation over time, after correction for back-exchange and dilution. On top, arrows refer to analysis at peptide level on panels C and D. (C, D) Relative percent of deuterium incorporation into each peptide (Figure S2CD) mapped onto the protein surface using a blue $(0 \%)$ to red $(100 \%)$ scale. For WT (C) and D93N (D), a top view along the 3-fold axis of the 6-mer (first column) and the dimer interface after splitting the two trimers (second column) are shown. The white contour outlines the fingerprint of the dimer interface. Residues with no data are coloured in black.

Figure 3. Unfolding pathway at full length and peptide level of D93N (A-B) and WT (C-D) MtNDPK. Each sample was pre-incubated during 16 hours at different concentrations of urea. Unfolding was monitored by intrinsic fluorescence (blue circles), residual enzymatic activity (red squares $)^{(53)}$ (A, C). The values are normalized to the experiment in the absence of urea. D93N unfolding was also monitored by a $12 \mathrm{sec}$ pulse labeling deuterium incorporation at full-length level (green diamond) (C). The relative percentage of deuterium incorporation measured at peptide level with a $12 \mathrm{sec} \mathrm{D}_{2} \mathrm{O}$ pulse for WT in 0, 3, 4, and $5 \mathrm{M}$ urea (B) and D93N in 0, 1, 2 and $3 \mathrm{M}$ urea (D) was mapped onto the crystal structure of $M t$-NDPK using a blue $(0 \%)$ to red $(100 \%)$ scale (Figure S3). A top view (left) and a split dimer interface (right) were shown. When the hexamer was dissociated or unfolded, it was split into three dimers or six randomly oriented monomers, respectively. The white contour on columns two and four outlines the fingerprint of the dimer interface.

Figure 4. Representative HD-XMS spectra, obtained during peptic peptide analysis for WT and D93N $M t$-NDPK after a 12 second pulse at different urea concentrations. The detailed experimental scheme is shown in the figure S3B. Mass spectra of the +2 charge state of peptides 9-21 and 25-35 
for the unlabeled sample and six HDX experiments in 0 to $6 \mathrm{M}$ urea are shown. WT: both peptides 9-21 (left) and 25-35 at the dimer interface (right) unfold at the same urea concentration 4-6 M (grey frames). D93N: Residues 9-21 (left) and 25-35 at the dimer interface (right) unfold at 0-1 M and 2-3 M urea, respectively (grey frames).

Figure 5. Unfolding and refolding pathways of WT $M t$-NDPK. (A) Refolding (blue lines) versus unfolding (red lines) pathways measured by intrinsic fluorescence (full circles) and enzyme activity (empty squares) after 16 hours pre-incubation in $\mathrm{GuHCl}^{(53)}$ The lines do not represent theoretical models but were drawn to help the reader. (B) Refolding and assembly pathway of WT $M t$-NDPK. The percentage of deuterium incorporation after 12 seconds $\mathrm{D}_{2} \mathrm{O}$ pulse at different refolding time is plotted onto the structure (Figure S4B). Six monomers in random orientation are drawn when unfolded. For each time point, a top view (left) and a split dimer interface of three split dimers (right) are shown. Residues with no data are colored in black. Note for refolding experiments that at this low protein concentration, only dimers are formed. Hexamers are formed at ten time higher concentrations. ${ }^{(53)}$ 